\title{
Effect of Synthesis Temperature on the Formation of GAC supported Pd and Au NPs
}

Kavita Meduri ${ }^{1}$, Candice Stauffer ${ }^{2}$, Thomas Lindner ${ }^{1}$, Graham O'Brien Johnson ${ }^{3}$, Paul G. Tratnyek ${ }^{3}$ and Jun Jiao $^{1,2}$

1. Department of Mechanical \& Materials Engineering, Portland State University, Portland, OR, USA.

2. Department of Physics, Portland State University, Portland, OR, USA.

3. Institute of Environmental Health, Oregon Health \& Science University, Portland, OR, USA.

Palladium (Pd) based catalysts are of increasing interest for the removal of volatile organic compounds (VOCs), such as trichloroethylene (TCE), from water by hydrogenolysis. Pd is often used in combination with promoter metals, such as gold $(\mathrm{Au})$, which can increase TCE reduction rates by up to X-fold [1]. As a support, Granular activated carbon (GAC) has several advantages, including its capacity to absorb contaminates, which concentrates the reactants at the catalyst surface. It also provides a high surface area (porous) or anchoring $\mathrm{Pd}$ and $\mathrm{Au}$ nanoparticles (NPs). Previously, we have reported the synthesis of $\mathrm{Pd} / \mathrm{Au} / \mathrm{GAC}$ at $70^{\circ} \mathrm{C}$ to achieve the Pd and Au NPs on 20-40 mesh GAC catalyst, which has rapidly degraded TCE in laboratory batch experiments [2].

To determine how temperature during synthesis affects the Pd and Au NP morphology and distribution on the GAC, and the reactivity of the resulting material, the catalysts were synthesized at two temperatures, $70^{\circ} \mathrm{C}$ and room temperature (RT), using a 2:1 molar ratio of Pd to Au precursor, with solvent acetone. These temperatures were chosen since $70^{\circ} \mathrm{C}$ is slightly hotter than the boiling point of acetone $\left(56^{\circ} \mathrm{C}\right)$, and RT $\left(22-25^{\circ} \mathrm{C}\right)$ is the most convenient temperature condition to maintain. SEM equipped with EDS was used to characterize the surface of the GAC grains. Figure 1 (a) shows a survey of NPs uniformly distributed the surface of GAC synthesized at RT. (b) shows the that NPs appear to be of two sizes, the cluster of small NPs in the range of 10-20 nm and the larger particles appear to be in the range of 60-90 $\mathrm{nm}$. (c) confirms the particles are composed of $\mathrm{Pd}$ and $\mathrm{Au}$. Chlorine $(\mathrm{Cl})$ and silicon $(\mathrm{Si})$ are contaminants of GAC introduced during handling. Figure 2 (a) shows the surface of the GAC-based catalyst synthesized at $70^{\circ} \mathrm{C}$, with (b) showing predominantly larger particles on the surface, in the range of 180-350 $\mathrm{nm}$. Figure 2 (c) confirms these NPs are composed of Pd and Au. As observed previously [2], the larger particles appear to be Au-rich, while the smaller particles tend to be Pd-rich. Our observations suggest that some of the formations are bimetallic, while others are elemental NPs or heterogeneous structures, further identification of which is the target of future work. We hypothesize that the difference in sizes of these NPs, between the catalysts synthesized with two different temperatures, is due to an increase in aggregation of Au NPs at the higher temperature.

As-produced catalysts show no remarkable distinguishing features visible to the naked eye, as seen in Figure 3 (a). The effect of NPs' size on the activity of the catalyst was tested via degradation of TCE in a hydrogen-rich aqueous atmosphere. Samples were analyzed using a gas chromatographer with a flameionized detector (GC/FID), and are reported in Figure 3 (b). The RT samples degraded TCE faster than $70^{\circ} \mathrm{C}$ sample, possibly because the RT samples offer more of the catalytically active NP surface than their counter-part, despite the fact that the same amount of precursors were used for synthesizing both samples. Further investigations are ongoing towards better particle size control and aggregation, and its impact on degradation of contaminants. In general, NP aggregation control can have several benefits across different applications. 
References:

[1] BP Chaplin, M Reinhard, WF Schneider, C Schu, JR Shapley, TJ Strathmann, and CJ Werth, Environ. Sci. Technol, 46 (2012), p. 3655

[2] K Meduri, A Barnum, GO Johnson, PG Tratnyek, and J Jiao, Microscopy and Microanalysis, 22 (2016), p. 332
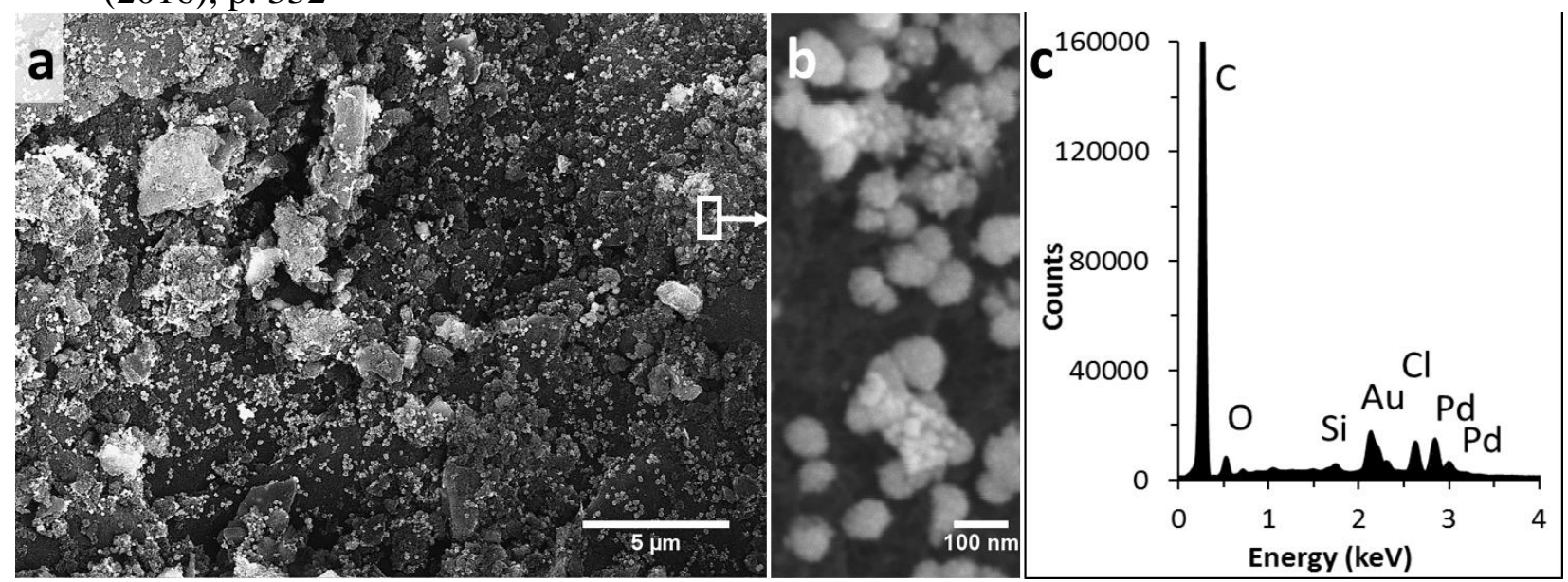

Figure 1. (a) SEM image at $11.5 \mathrm{kX}$ of the surface of the RT synthesized catalyst. (b) $220 \mathrm{kX}$ image showing the NPs morphology. (c) is the EDS spectrum confirming Pd and Au composition of NPs.
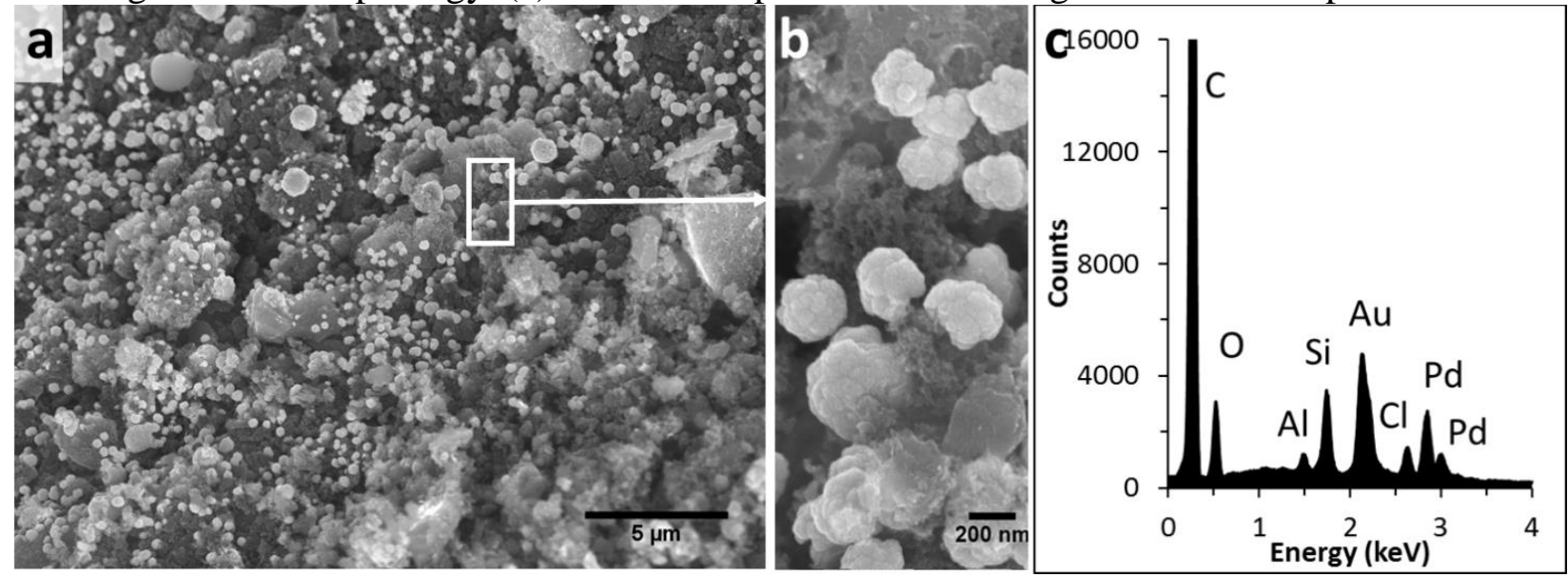

Figure 2. (a) SEM image at $11.5 \mathrm{kX}$ mag of the surface of $70^{\circ} \mathrm{C}$ synthesized catalyst. (b) $100 \mathrm{kX}$ image showing the NPs morphology. (c) is the EDS spectrum confirming Pd and Au composition of NPs.
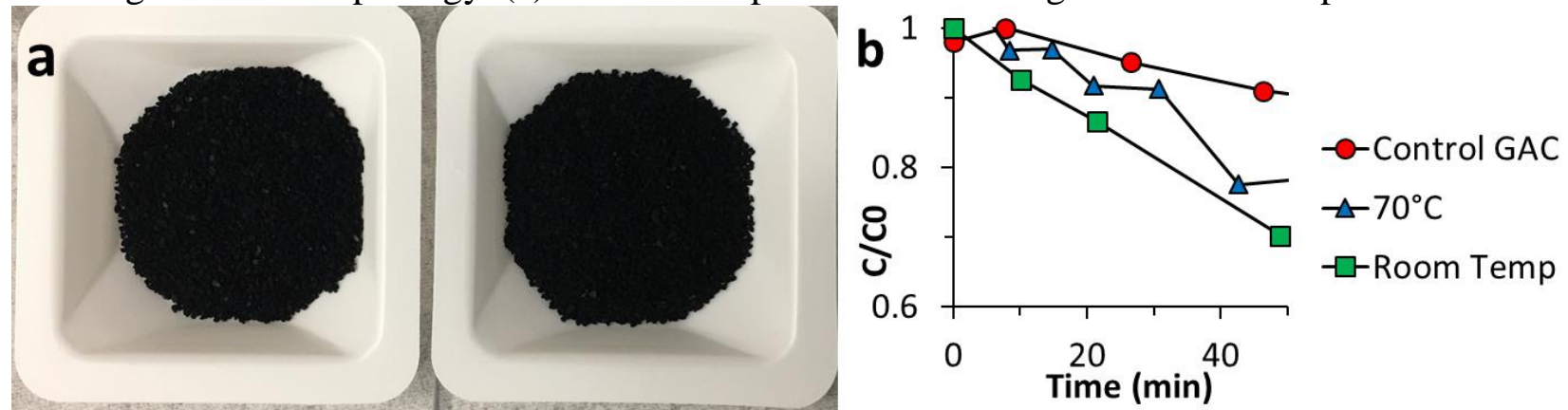

Figure 3. (a) Pictures of samples fabricated at room temperature (right) and $70^{\circ} \mathrm{C}$ (left). (b) shows the TCE degradation rates of the samples. 